\title{
Impact of Husbands' Healthcare Decision Making on Women's Future Intention of Using Contraceptives in Bangladesh
}

\author{
Most. Sonia Khatun ${ }^{1}$, A H M Musfiqur Rahman Nabeen ${ }^{1}$, Md. Maidul Husain ${ }^{2}$ and Md. Abdus Salam \\ Akanda $^{3 *}$ \\ ${ }^{1}$ Department of Statistics, Pabna University of Science and Technology, Pabna-6600, Bangladesh \\ ${ }^{2}$ Department of Statistics, BSMR Science \& Technology University, Gopalganj-8100, Bangladesh \\ ${ }^{3}$ Department of Statistics, Dhaka University, Dhaka-1000, Bangladesh
}

(Received : 27 November 2019; Accepted : 4 October 2020)

\begin{abstract}
The use of contraceptive is important for the reduction of maternal mortality, child mortality and to slow down the high population growth rate. The central objective of this study is to examine the association between husbands' involvement with healthcare decision making and women's future intention of using contraceptives. Bangladesh Demographic and Health Survey (BDHS), 2014 data is used for this purpose. To evaluate the association overall and stratified binary logistic regression models are employed as well as the odds ratios (OR) along with their 95\% confidence intervals are specified. The adjusted effect of overall model shows that husband's involvement with healthcare decision making is significantly negatively associated $(\mathrm{OR}=0.82,95 \% \mathrm{CI}$ : $0.70,0.95)$ with women's intention of using contraceptives. The adjusted effects of stratified models also demonstrate that the association is significantly negative among women in rural area, from middle income families, who are Muslim, having more than two living children, having current age 35 to 49 , who are unemployed, whose husbands are 1 to 5 years older and secondary educated. These findings can help to address the men's role in family planning and to increase the current contraceptive prevalence rate in Bangladesh.
\end{abstract}

Keywords: Contraceptive, healthcare decision, contraceptive prevalence rate, odds ratio, Bangladesh.

\section{Introduction}

Bangladesh is the world's number tenth and Asia's number sixth densely populated country. In 2018, its total population becomes $166,368,149$ and the density becomes the highest $\left(1278 / \mathrm{km}^{2}\right)$ among all the neighboring countries (United Nations Department of Economic and Social Affairs, 2018). The huge population of Bangladesh creates some typical problems like food insecurity, unplanned urbanization and economic inequality which are also associated with child and maternal health complicacies. ${ }^{1-3}$ Thus reduction of population growth should be a prioritized task for Bangladesh government. It has been widely accepted that family planning can control the unintended pregnancies and can decrease the rate of population growth. 4

In developing countries every year over 22 million risky abortions are occurring and causing about 47,000 maternal deaths. ${ }^{6,7}$ At least one third of these unexpected maternal deaths can be avoided by using contraceptives. ${ }^{8}$ According to Bangladesh Demographic and Health Survey (BDHS), 2014 data the contraceptive prevalence rate (CPR) was $62 \%$ in $2014^{9}$. Compared to 1975 when the rate was only $8 \%$, it has increased significantly but the rate of progress has been slowed down over the last fifteen years. It was 58\% in 2004 which indicates that within a decade the rate has increased only four percentage points. ${ }^{9}$ Therefore, it is necessary to critically examine the aspects of contraceptives in Bangladesh.

In developing countries like Bangladesh, women are supposed to take the responsibilities of contraception and usually they face complicated and challenging intricacies to use modern contraceptives. ${ }^{11,13}$ The complex interaction of social, demographic, economic and cultural factors are responsible behind these challenges. ${ }^{4,10-12}$ Nevertheless the influence of husbands on the attitude of wives' contraceptive using is becoming one of the important areas for the reproduction health researchers. In Bangladesh, it is quite rare to use contraceptive under husband's disapproval. $^{13}$ Many previous studies of developing countries imply that the male partners play an important role on female counterpart's decision on using contraceptives. $^{14-16}$ Even higher educated women who intend to use contraceptive are sometimes not able to use it because of their husband's attitudes, dissatisfactions and fertility preferences. ${ }^{14,17}$ It is found that couple's combined decision making has a stronger positive influence on contraceptive use. ${ }^{15}$ A study among Mozambican women gives substantial evidence of the association between husbands' healthcare decision making power and women's intention of using contraceptives. A very limited number of studies have been conducted in Bangladesh about the effect of a husband's healthcare decision making on a woman's future intention of using contraceptives. Thus, this study intends to critically examine the relationship between husband's involvement with healthcare decision making and women's future intention of using contraceptives in Bangladesh.

\section{Data and Methodology}

A national representative Bangladesh Demographic and Health Survey (BDHS), 2014 data is used for this study. It was conducted by National Institute of Population Research and Training (NIPORT), Bangladesh using two-stage stratified sampling design. In total around 18,000 households were selected and interviewed ever-married women from each household to get demographic, health 
related and socioeconomic information of the ever-married women. The details of the survey design can be obtained from BDHS report, 2014. ${ }^{9}$

\section{Outcome variable}

The outcome variable of this study is women's future intention of using modern contraceptive. In BDHS, 2014 data the original variable was 'contraceptive use and intention' with five possible categories: using modern method, using traditional method, non-user - intends to use later, does not intend to use and never had sex. Those in using a modern method or using a traditional method or never had sex categories are excluded from the current analysis. Consequently, the outcome variable is dichotomized as: intends to use and doesn't intend to use contraceptives in future.

\section{Central exposure of interest}

In this study, the central exposure of interest is the husband's decision making power on respondent's healthcare. The possible responses of the original question about respondent's healthcare decision maker were: respondent by herself, respondent and husband in cooperation, husband alone, respondent and other person, someone else and other. The latter three groups are excluded in present analysis as they are irrelevant with research interest. Therefore the central exposure of interest is dichotomized as husband alone and respondent by herself or in cooperation with husband. The justification behind this categorization is that the number of women taking their health care decision by themselves is trivial and the research interest is to assess whether husband's healthcare decision making is responsible for the respondent's future intention of using contraceptive.

\section{Potential confounder}

Based on literature review ${ }^{10,11,20,21}$ following potential confounders are selected in the study: as place of residence, division, educational attainment of women, wealth index, religion, number of living children, women's current age, women's working status, age difference of woman and husband, and husband's educational attainment.

\section{Binary logistic regression model}

Let us consider binary response variable $y_{i} ; i=1,2, \ldots, n$ (intention of contraceptive use) which can take two values either yes " 1 " or no " 0 " for an ever-married woman, and corresponding independent variables $\boldsymbol{X}$. Let $\pi(x)$ denotes the probability of having intention to use contraceptives when $\boldsymbol{X}$ takes value $x$. In logistic regression model, for an individual $y_{i}$, the probability $\pi(x)$ can be defined in terms of logit link function as ${ }^{18}$

$$
\operatorname{logit}(\pi(x))=\log \left(\frac{\pi(x)}{1-\pi(x)}\right)=\alpha+\beta x
$$

In terms of success probability, the logistic regression model can be defined as

$$
\pi(x)=\frac{\exp (\alpha+\beta x)}{1+\exp (\alpha+\beta x)} .
$$

The parameter $\beta$ determines the effect of covariates on the probability of intention to use contraceptives. The parameters of the model are estimated using the maximum likelihood method. ${ }^{19}$

\section{Process of getting unadjusted and adjusted odds ratio, and} stratification

The unadjusted association is obtained from univariate logistic regression whereas adjusted association can be obtained from multivariate logistic regression model. That is, when the interest is to assess 'women's future intention of using contraceptive' by only 'husband's decision making on respondent's healthcare' then unadjusted odds ratio is obtained. On the other hand, the adjusted odds ratio can be obtained when 'husband's decision making on respondent's healthcare' variable is used as independent variable in the logistic regression along with other potential confounders.

In this study, the association between husbands' involvement with healthcare decision making and women's future intention of using contraceptives is further examined through stratification by the different categories of the potential confounders. For instance, by 'place of residence' variable two stratum is obtained- urban and rural. Then, the association is assessed in each stratum.

\section{Results}

The analysis of this study is mainly carried out by four phases: descriptive statistics, bivariate analysis, univariate and multivariate logistic regression analysis, and univariate and multivariate logistic regression analysis by stratification. The results are discussed in this following section.

\section{Descriptive statistics}

The weighted distribution of ever-married women with regard to selected confounders is shown in the Table 1. It shows about $55.8 \%$ women have future intention to use contraceptive whereas $44 \%$ don't have intention. In case of respondent's health care decision making 68.1\% women report that they themselves or in cooperation with their husband take the decision while $31.9 \%$ report that their husbands take the decision singlehandedly.

\section{Bivariate analysis}

In order to execute bivariate association, chi-square $\left(\chi^{2}\right)$ test is performed. It reveals whether a particular confounder is related with the outcome variable (future intention of contraception). The results are shown in the Table 1. It demonstrates that at $1 \%$ level of significance all the confounders are significantly associated with future intention of contraception. 
Table 1. The weighted distribution of ever-married women with regard to selected confounders and the $p$-values of chi-square $\left(\chi^{2}\right)$ test

\begin{tabular}{|c|c|c|c|c|}
\hline \multirow[b]{2}{*}{ Variables $(n=$ sample size $)$} & \multicolumn{3}{|c|}{ Future intention of contraception } & \multirow[b]{2}{*}{ p-value } \\
\hline & Weighted \% & $\begin{array}{c}\text { Having intention } \\
(\%)\end{array}$ & $\begin{array}{c}\text { Not having } \\
\text { intention }(\%)\end{array}$ & \\
\hline Husband's decision on respondent's healthcare & & & & $<0.001$ \\
\hline Women alone or jointly (3826) & 68.1 & $2133(55.8)$ & $1693(44.2)$ & \\
\hline Husband alone (1925) & 31.9 & $1072(55.6)$ & $853(44.4)$ & \\
\hline Place of residence & & & & $<0.001$ \\
\hline Urban (1818) & 26.1 & $1005(57.5)$ & $813(42.5)$ & \\
\hline Rural (3933) & 73.9 & $2200(55.2)$ & $1733(44.8)$ & \\
\hline Division & & & & $<0.001$ \\
\hline Barisal (702) & 6.2 & $392(56.4)$ & $310(43.6)$ & \\
\hline Chittagong (1082) & 21.3 & $687(62.5)$ & $395(37.5)$ & \\
\hline Dhaka (982) & 34.3 & $562(55.1)$ & $420(44.9)$ & \\
\hline Khulna (715) & 9.0 & $348(49.6)$ & $367(50.4)$ & \\
\hline Rajshahi (676) & 10.1 & $348(52.4)$ & $328(47.6)$ & \\
\hline Rangpur (683) & 9.6 & $362(51.9)$ & $321(48.1)$ & \\
\hline Sylhet (911) & 9.4 & $506(56.5)$ & $405(43.5)$ & \\
\hline Educational attainment of women & & & & $<0.001$ \\
\hline No education (1378) & 25.5 & $374(27.9)$ & $1004(72.1)$ & \\
\hline Primary $(1669)$ & 29.4 & $883(54.2)$ & $786(45.8)$ & \\
\hline Secondary (2163) & 36.9 & 1537 (71.8) & $626(28.2)$ & \\
\hline Higher (541) & 8.1 & $411(76.9)$ & $130(23.1)$ & \\
\hline Wealth Index & & & & $<0.001$ \\
\hline Poor (2090) & 38.3 & $1140(53.9)$ & $950(46.1)$ & \\
\hline Middle (1179) & 19.6 & $641(54.8)$ & $538(45.2)$ & \\
\hline Rich (2482) & 42.1 & $1424(58.0)$ & $1058(42.0)$ & \\
\hline Religion & & & & $<0.001$ \\
\hline Muslim (5275) & 91.7 & $2973(56.3)$ & $2302(43.7)$ & \\
\hline Non-Muslim (476) & 8.3 & $232(50.3)$ & $244(49.7)$ & \\
\hline Number of living children & & & & $<0.001$ \\
\hline$\leq 2(3782)$ & 65.2 & $2617(69.3)$ & $1165(30.7)$ & \\
\hline More than 2 (1969) & 34.8 & $588(30.6)$ & $1381(69.4)$ & \\
\hline Women's current age & & & & $<0.001$ \\
\hline $15-24(1835)$ & 32.6 & $1626(87.5)$ & $209(12.5)$ & \\
\hline $24-34(1704)$ & 29.6 & $1251(73.0)$ & $453(27.0)$ & \\
\hline $35-49(2212)$ & 37.8 & $328(15.0)$ & $1884(85.0)$ & \\
\hline Women's working Status & & & & $<0.001$ \\
\hline Employed (1505) & 28.5 & $715(47.6)$ & $790(52.4)$ & \\
\hline Unemployed (4246) & 71.5 & $2490(59.1)$ & $1756(40.9)$ & \\
\hline Woman and husband age difference & & & & $<0.001$ \\
\hline Husband younger or same age (83) & 1.5 & $50(62.7)$ & $33(37.3)$ & \\
\hline $1-5$ years older $(1488)$ & 26.2 & $988(66.2)$ & $500(33.8)$ & \\
\hline $6-10$ years older $(2217)$ & 38.4 & $1341960.4)$ & $876(39.6)$ & \\
\hline$>10$ years older $(1963)$ & 33.9 & $826(42.3)$ & $1137(57.7)$ & \\
\hline Husband's educational attainment & & & & $<0.001$ \\
\hline No education (1583) & 28.9 & $666(41.7)$ & $917(58.3)$ & \\
\hline Primary (1544) & 27.1 & $913(59.4)$ & $631(40.6)$ & \\
\hline Secondary (1778) & 30.8 & $1098(62.5)$ & $680(37.5)$ & \\
\hline \multirow[t]{2}{*}{ Higher (846) } & 13.2 & $528(64.0)$ & $318(36.0)$ & \\
\hline & & 55.8 & 44.2 & \\
\hline
\end{tabular}

Univariate and multivariate logistic regression

The unadjusted and adjusted results obtained from univariate and multivariate logistic regression analysis respectively are shown in the Table 2 . The adjusted result of Table 2 indicates significant association between women's future intention of using contraceptives and husband's involvement with healthcare decision making. It shows that the women whose husbands are their ultimate healthcare decision maker are $18 \%$ less likely to have future intention of using contraceptives compared to the women who take their healthcare decision by themselves or with their husbands jointly. 
Table 2. Unadjusted and adjusted odds ratio with $95 \%$ CI for the studied covariates

\begin{tabular}{|c|c|c|}
\hline Variables $(n=$ sample size $)$ & Unadjusted OR (95\% CI) & Adjusted OR (95\% CI) \\
\hline \multicolumn{3}{|c|}{ Husband's decision on respondent's healthcare } \\
\hline Husband alone (1925) & $0.98(0.89,1.11)$ & $0.82(0.70,0.95)$ \\
\hline${ }^{\mathrm{R}}$ Urban (1818) & 1.00 & 1.00 \\
\hline Rural (3933) & $1.02(0.92,1.15)$ & $1.09(0.91,1.29)$ \\
\hline \multicolumn{3}{|l|}{ Division } \\
\hline Chittagong (1082) & $1.30(1.09,1.55)$ & $1.25(0.98,1.59)$ \\
\hline${ }^{\mathrm{R}}$ Dhaka (982) & 1.00 & 1.00 \\
\hline Khulna (715) & $0.71(0.58,0.6)$ & $0.81(0.61,1.06)$ \\
\hline Rajshahi (676) & $0.79(0.65,0.97)$ & $0.87(0.66,1.41)$ \\
\hline Rangpur (683) & $0.84(0.69,1.03)$ & $1.04(0.79,1.38)$ \\
\hline Sylhet (911) & $0.93(0.78,1.12)$ & $0.82(0.64,1.06)$ \\
\hline Secondary (2163) & $6.59(5.67,7.67)$ & $2.52(1.99,3.18)$ \\
\hline Higher (541) & $8.49(6.76,10.71)$ & $4.60(3.19,6.65)$ \\
\hline \multicolumn{3}{|l|}{ Wealth Index } \\
\hline Poor (2090) & $1.01(0.87,1.16)$ & $1.06(0.86,1.29)$ \\
\hline${ }^{\mathrm{R}}$ Middle (1179) & 1.00 & 1.00 \\
\hline Rich (2482) & $1.13(0.98,1.30)$ & $1.10(0.90,1.36)$ \\
\hline \multicolumn{3}{|l|}{ Religion } \\
\hline Muslim (5275) & $1.36(1.13,1.64)$ & $1.15(0.89,1.49)$ \\
\hline${ }^{\mathrm{R}}$ Non-Muslim (476) & 1.00 & 1.00 \\
\hline \multicolumn{3}{|l|}{ Number of living children } \\
\hline $\mathrm{R}^{\mathrm{N}} \leq 2(3782)$ & 1.00 & 1.00 \\
\hline \multicolumn{3}{|l|}{ Woman and husband age difference } \\
\hline${ }^{\mathrm{R}}$ Husband younger or same age (83) & 1.00 & 1.00 \\
\hline $1-5$ years older $(1488)$ & $1.30(0.82,2.04)$ & $1.50(0.83,2.66)$ \\
\hline $6-10$ years older $(2217)$ & $1.01(0.64,1.57)$ & $1.09(0.61,1.92)$ \\
\hline > 10 years older $(1963)$ & $0.48(0.30,0.75)$ & $0.65(0.36,1.15)$ \\
\hline \multicolumn{3}{|l|}{ Husband's educational attainment } \\
\hline${ }^{\mathrm{R}}$ No education (1583) & 1.00 & 1.00 \\
\hline Primary (1544) & $1.99(1.73,2.30)$ & $1.14(0.93,1.40)$ \\
\hline Secondary (1778) & $2.22(1.94,2.55)$ & $0.90(0.72,1.12)$ \\
\hline Higher (846) & $2.29(1.93,2.71)$ & $0.83(0.62,0.12)$ \\
\hline
\end{tabular}

${ }^{\mathrm{R}}$ Reference category

Univariate and multivariate logistic regression by stratification

The unadjusted and adjusted results obtained from univariate and multivariate logistic regression through stratification are shown in Table 3. The adjusted results of stratified model demonstrate that the relationship is significantly negative among women in rural area, from middle income families, who are Muslim, having more than two living children, having current age 35 to 49, who are unemployed, whose husbands are 1 to 5 years older and secondary educated. In case of rural women, it is observed that the women whose husbands are their final healthcare decision maker are $18 \%$ less likely to have future intention of using contraceptives compared to the women who take their healthcare decision by themselves or with their husbands in cooperation. Likewise, in the midst of the women from middle class 
families the women whose husbands alone take decision about their health are $32 \%$ less likely to have future intention of using contraceptives. Among the Muslim women the women whose husbands are solely responsible for their healthcare decision are $19 \%$ less likely to have future intention of using contraceptives. Similarly, among the women having more than 2 living children, current age 35 to
49, currently unemployed, whose husbands are 1 to 5 years older and secondary educated, the women whose husbands take healthcare decision alone are 38\%, 38\%, 24\%, 32\% and $26 \%$ less likely to have future intention of using contraceptives respectively compared to the women who take their healthcare decision by themselves or with their husbands jointly.

Table 3. Unadjusted and adjusted odds ratio of husband's decision making power on respondent's healthcare with 95\% CI obtained from logistic regression by stratification

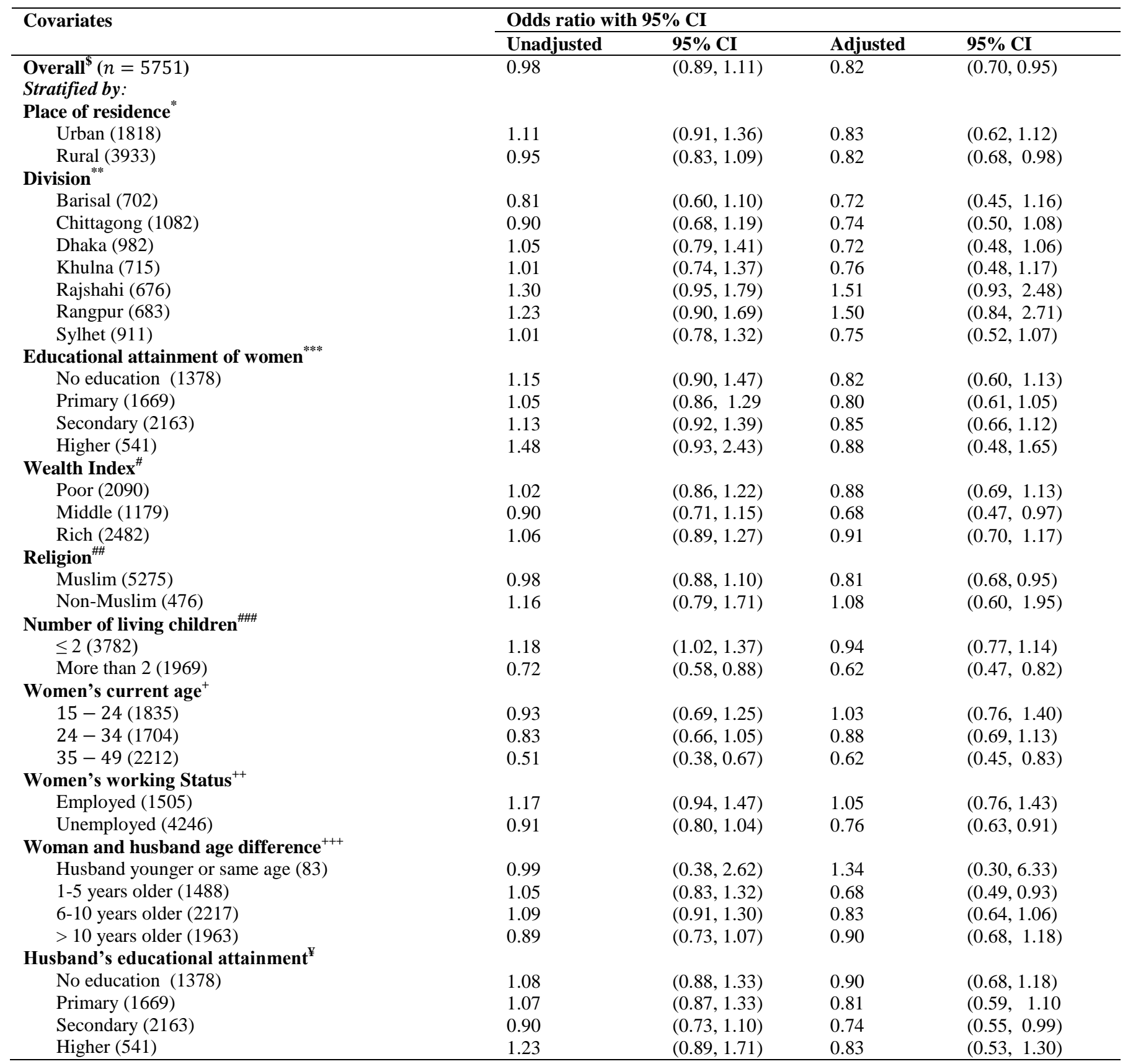

${ }^{\$}$ Logistic model adjusted for place of residence, division, educational attainment of women, wealth index, religion, number of living children, women's current age, mother's working status, woman and husband age difference, husband's educational attainment.

*Logistic model adjusted for the entire confounding variables given above excluding place of residence.

** Logistic model adjusted for the entire confounding variables given above excluding division.

${ }^{* * *}$ Logistic model adjusted for the entire confounding variables given above excluding educational attainment of women. 
"Logistic model adjusted for the entire confounding variables given above excluding wealth index.

\#\#Logistic model adjusted for the entire confounding variables given above excluding religion.

\#\#\# Logistic model adjusted for the entire confounding variables given above excluding number of living children.

${ }^{+}$Logistic model adjusted for the entire confounding variables given above excluding women's current age.

${ }^{++}$Logistic model adjusted for the entire confounding variables given above excluding women's working status.

${ }^{+++}$Logistic model adjusted for the entire confounding variables given above excluding woman and husband age difference.

${ }^{\mathrm{z}}$ Logistic model adjusted for the entire confounding variables given above excluding husband's educational attainment.

\section{Discussion}

In this study, an initiative has been taken to identify the relationship between husband's involvement with healthcare decision making and women's future intention of using contraceptives in Bangladesh. It is observed that among the currently non-users of contraceptives about $44 \%$ women don't have the future intention of using contraceptives. This indication of not having an intention to use contraceptives by this huge number of non-user women has a serious effect on the improvement of current contraceptive prevalence rate (CPR). The increase of CPR is necessary to decrease high fertility rate and for the betterment of maternal as well as child health. ${ }^{22}$ It is detected that among the women who don't have any formal education approximately $72 \%$ of them don't have future intention to use contraceptives. Similarly, amid the women whose husbands don't have formal education, 58\% don't have the future intention of using contraceptives. This indicates that education is a crucial factor to increase CPR.

The findings of the study indicate that there is a significant association between husband's involvement with healthcare decision making and women's future intention of using contraceptives. The women who report that their husbands take their healthcare decision single-handedly are $18 \%$ less likely to have the intention of using contraceptives in future. Thus the absolute power of the husbands about taking healthcare decision of their wives is an important barrier for the women's future intention of using contraceptives in Bangladesh. These results are similar to the findings of other developing countries. ${ }^{15,16,21}$

The association between husband's involvement with healthcare decision making and women's future intention of using contraceptives is significant among rural women and not significant in the midst of urban women. This is because urban women are more aware of family planning services than rural women and the availability of these services in urban areas. Since the Muslim families are more restrictive about family planning, the association becomes significant among Muslim women. As the women from middle-class families, having already more than two children, from age group 35 to 49 year have less independent choices, the association between husband's involvement with healthcare decision making and women's future intention of using contraceptives turns out to be significant. Similarly, the association is significant among unemployed women because they rely mostly on their husbands. Hence the obstacle of husband's influence on woman's intention of using contraceptives has to be addressed by the family planning authority to increase CPR in Bangladesh.

\section{Conclusion}

Women's future intention of using contraceptives is a vital indicator to evaluate the demand of family planning. Likewise, who is the health care decision maker for the women of reproductive age is an important indicator to assess women's health in Bangladesh. This study indicates that husbands' involvement with healthcare decision making has significant impact on women's future intention of using contraceptives. Particularly the relationship is substantial among the women in rural area, from middle income families, who are Muslim, having more than two living children, having current age 35 to 49 , who are unemployed, whose husbands are 1 to 5 years older and secondary educated. The significant association emphasizes the need of aiming male people for their larger participation in contraception oriented programs. This study has several limitations. It is incapable to judge why and how a husband's health care decision making power influences a woman's future intention of using contraception. This study is not capable to take into account the possible effect of unmet contraceptive requirements of women in Bangladesh. It is also unable to adjust the past experiences of the respondents (like side effects of the contraceptives) which may manipulate the tendency of using contraceptives in future.

The study findings suggest that husbands' involvement with healthcare decision about their wives has substantial influence on wives' future intention of using contraceptives. The following recommendations are made based on the analysis of this study to increase the contraceptive prevalence rate in Bangladesh.

(i) Awareness programs should be taken to instruct husbands about reproductive health matters, contraceptives, women's health, pregnancy, birth spacing etc.

(ii) Innovative approaches are needed to make the husbands cooperative with their wives especially in healthcare related issues such that they can make health care related decision jointly.

(iii) Husbands' decision making power has significant impact on women's future intention of using contraceptives in rural and middle income families. Thus, planners should address male attitude about contraceptive use in rural areas and in middle income families. 
(iv) The significant association among the women who are unemployed, having more than two living children, having current age 35 to 49 strengthens the necessity of targeting these groups by the government.

(v) Husbands should be made as facilitators for the overall improvement of reproductive health condition in Bangladesh.

\section{Acknowledgement}

We are grateful to the Department of Statistics, Pabna University of Science and Technology, Pabna and Department of Statistics, University of Dhaka, Bangladesh for giving us permission to use their logistic supports. We are also indebted to the authorities of the National Institute of Population Research and Training (NIPORT), Bangladesh for allowing us to use the Bangladesh Demographic and Health Survey, 2014 data.

\section{References}

1. Streatfield, P. K. and Z. A. Karar, 2008. Population challenges for Bangladesh in the coming decades. Journal of Health, Population, and Nutrition, 26(3), 261.

2. Islam, A. and T. Biswas, 2014. Chronic non-communicable diseases and the healthcare system in Bangladesh: current status and way forward. Chronic Diseases International, 1(2), 6 .

3. Nabeen, A. H. M. M. R. and M. A. S. Akanda, 2018. Association between economic inequality and under-five child malnutrition: Evidence from Bangladesh Demographic and Health Survey. Dhaka University Journal of Science, 66(1), 73-78.

4. Islam, M. S., 2014. Socio-demographic factors differently associate with contraceptive use among older women in comparison with younger women in Bangladesh. Research on Humanities and Social Sciences, 5(4), 50-57.

5. Huda, F. A., Y. Robertson, S. Chowdhuri, B. K.Sarker, L. Reichenbach and R. Somrongthong, 2017. Contraceptive practices among married women of reproductive age in Bangladesh: A review of the evidence. Reproductive Health, 14(1), 69 .

6. Ahman E and I. H. Shah, 2011. New estimates and trends regarding unsafe abortion mortality. International Journal of Gynecology and Obstetrics, 115(2), 121-126.

7. Ahmed, S., Q. Li, L. Liu and A. O. Tsui, 2012. Maternal deaths averted by contraceptive use: An analysis of 172 countries. Lancet, 380 (9837), 111-125.

8. Tsui A.O., R. McDonald-Mosley and A. E .Burke, 2010. Family planning and the burden of unintended pregnancies. Epidemiologic Reviews, 32(1), 152-174.

9. BDHS (2014). Bangladesh demographic and health survey data \& report. Niport, Dhaka, Bangladesh; Mitra and Associates, Dhaka, Bangladesh.
10. Khan M. M., M. E. Hossain and M. N. Hoq, 2012. Determinants of contraception use among female adolescents in Bangladesh. Asian Social Science, 12(8), 181-191.

11. Hossain B. M., M. H. R. Khan, F. Ababneh and J. E. H. Shaw, 2018. Identifying factors influencing contraceptive use in Bangladesh: Evidence from BDHS 2014 data. BMC Public Health, 18(1), 192.

12. Sensoy N, Y. Korkut, S. Akturan, M. Yilmaz, C. Tuz and B. Tuncel, 2018. Factors affecting the attitudes of women toward family planning. http://dx.doi.org/10.5772/ intechopen.73255.

13. Kamal N., 2000. The influence of husbands on contraceptive use by Bangladeshi women. Health Policy and Planning, 15(1), 43-51.

14. Casterline J. B., Z. A. Sathar and U. M. Huque, 2001. Obstacles in contraceptive use in Pakistan: A study in Punjab. Studies in Family Planning, 32(2), 95-110.

15. Hameed W., S. K. Azmat, M. Ali, M. L. Sheikh,G. Abbas, M. Temmerman and B. I. Avan, 2014. Women's empowerment and contraceptive use: the role of independent versus couples' decision-making, from a lower middle income country perspective. PLoS One, 9(8):e104633. doi:10.1371/journal.pone.0104633.

16. Mboane R. and B. P. Bhatta, 2015. Influence of a husband's healthcare decision making role on a woman's intention to use contraceptives among Mozambican women. Reproductive Health, 12, 36. doi: 10.1186/s12978-015-00102.

17. Akinrinola B., 1995. Desired fertility and fertility behavior among the Yoruba of Nigeria: A study of couple preferences and subsequent fertility. Population Studies, 49(2), 317-28.

18. Sharma S. S., D. G. Kleinbaum and L. L. Kupper, 1978. Applied regression analysis and other multivariate methods, doi: $10.2307 / 3150614$.

19. Lee E. T., J. W. Wang, 2003. Statistical methods for survival data analysis, $3^{\text {rd }}$ edition, 428-432.

20. Ujah O. I., A. N.Ocheke, J. T.Mutihir, J. A. Okopi and I. A. O. Ujah, 2017. Postpartum contraception: Determinants of intention and methods of use among an obstetric cohort in a tertiary hospital in Jos, North Central Nigeria. International Journal of Reproduction, Contraception, Obstetrics and Gynecology, 6(12), 5213-5218.

21. Abraha T. H., H. S. Belay and G. M.Welay, 2018. Intentions on contraception use and its associated factors among postpartum women in Aksum town, Tigray region, northern Ethiopia: A community-based cross-sectional study. Reproductive Health, 15(1), 188, https://doi.org/10.1186 /s12978-018-0632-2.

22. Chola L, S. McGee, A. Tungendhaft, E. Buchmann and K. Hofman, 2015. Scaling up family planning to reduce maternal and child mortality: The potential costs and benefits of modern contraceptive use in South Africa. PLoS One, 10(6):e0130077, doi: 10.1371/journal.pone.0130077. 
